\title{
Um ensaio de antropologia visual sobre o cotidiano de trabalhadores durante a pandemia da COVID-19 em Cascavel - PR
}

An essay of visual anthropology on daily life of workers during the COVID-19 pandemic in Cascavel - PR, Brazil

Un ensayo de antropología visual sobre el cotidiano de los trabajadores durante la pandemia del COVID-19 en Cascavel - PR

Fábio Lopes Alves ORCID: https://orcid.org/0000-0002-2114-3831 Universidade Estadual do Oeste do Paraná, Brasil E-mail: fabiobidu@ @otmail.com

Claudia Barcelos de Moura Abreu ORCID: https://orcid.org/0000-0001-8814-1235 Universidade Federal de São Paulo, Brasil E-mail: claudia.abreu@unifesp.br

Tania Maria Rechia Schroeder ORCID: https://orcid.org/0000-0002-3646-3088 Universidade Estadual do Oeste do Paraná, Brasil E-mail: tania.rechia@hotmail.com

Valdecir Soligo

ORCID: https://orcid.org/0000-0003-2618-009X Universidade Estadual do Oeste do Paraná, Brasil E-mail: valdecir_soligo@yahoo.com.br

Marco Antonio Batista Carvalho ORCID: https://orcid.org/0000-0002-6811-2661 Universidade Estadual do Oeste do Paraná, Brasil

E-mail: marcoab_carvalho@yahoo.com.br

Adrian Alvarez Estrada

ORCID: https://orcid.org/0000-0002-0980-8925 Universidade Estadual do Oeste do Paraná, Brasil E-mail: adrianalvarez.estrada@gmail.com

Carlos Eduardo de Castro

ORCID: https://orcid.org/0000-0002-3944-1642

Universidade Estadual do Oeste do Paraná, Brasil

E-mail: cadudecastro@ terra.com.br

\begin{abstract}
Resumo
O presente ensaio de Antropologia Visual tem o objetivo de narrar, imageticamente, por meio de uma fotoetnografia, o cotidiano citadino de trabalhadores, em suas múltiplas experiências que, em função das condições sociais ou da profissão que exercem, não têm condições de cumprir as recomendações do distanciamento social, durante a pandemia da COVID-19, na cidade de Cascavel-PR. O artigo encontra-se estruturado em duas partes. Na primeira, formada por um texto escrito, recorremos ao conceito de apartheid, como perspectiva de análise para mostrar seus efeitos no cotidiano de trabalhadores; assim, apresentamos, brevemente, o campo de Antropologia Visual e da fotoetnografia. Por fim, discorremos sobre nosso campo de pesquisa, marcado por profundas evidências de vulnerabilidade e injustiça social. Na segunda parte, formada, essencialmente, por uma linguagem imagética, apresentamos o cotidiano dos nativos. Com essa organização, ao recorrermos às linguagens textual e imagética, oferecemos ao leitor duas possibilidades de entrada para percorrer os múltiplos corredores de interpretações, sendo possível escolher entre iniciar a leitura pelas imagens ou pela escrita textual.
\end{abstract}

Palavras-chave: COVID-19; Antropologia visual; Fotoetnografia; Pandemia.

\begin{abstract}
This essay on Visual Anthropology aims to narrate, imagetically, through a photoetnography, the daily life of workers, in their multiple experiences that, due to the social conditions or the profession they exercise, are unable to comply with the social distance recommendations during the COVID-19 pandemic, in the city of Cascavel-PR, Brazil. The article is structured in two parts. In the first, formed by a written text, we resort to the concept of apartheid, as a perspective of analysis to show its effects in the daily lives of workers; thus, we briefly present the field of Visual
\end{abstract}


Anthropology and photoetnography. Finally, we discuss our research field, marked by profound evidence of vulnerability and social injustice. In the second part, essentially formed by an imagetic language, we present the daily life of the natives. With this organization, resorting to textual and imagery languages, we offer the reader two input possibilities to cycle through multiple corridors of interpretations, being possible to choose between starting reading through images or through textual writing.

Keywords: COVID-19; Visual anthropology; Photoetnography; Pandemic.

\section{Resumen}

Este ensayo de Antropología Visual tiene como objetivo narrar, por imágenes, a través de una fotoetnografía, la vida cotidiana citadina de los trabajadores, en sus múltiples vivencias que, por las condiciones sociales o la profesión que ejercen, son incapaces de cumplir con las recomendaciones de la distancia social, durante la pandemia de COVID-19, en la ciudad de Cascavel-PR. El artículo está estructurado en dos partes. En el primero, formado por un texto escrito, recurrimos al concepto de apartheid, como perspectiva de análisis para exponer sus efectos en la vida cotidiana de los trabajadores; así, presentamos, brevemente, el campo de la Antropología Visual y la fotoetnografía. Finalmente, discutimos nuestro campo de investigación, marcado por profundas evidencias de vulnerabilidad e injusticia social. En la segunda parte, esencialmente formada por un lenguaje visual, presentamos la vida cotidiana de los nativos. Con esta organización, cuando utilizamos lenguajes textuales e de imágenes, ofrecemos al lector dos posibilidades de entrada para recorrer los múltiples corredores de interpretaciones, pudiendo elegir entre comenzar a leer a través de imágenes o mediante escritura textual.

Palabras clave: COVID-19; Antropología visual; Fotoetnografía; Pandemia.

\section{Introdução}

"Quais são as imagens do mundo do trabalho que povoam nossas memórias, nossos corpos, nossos afetos, nossas práticas e nossos saberes?” Foi com essa pergunta que Rocha e Eckert (2015, p. 16) problematizaram, antropologicamente, a questão da memória do trabalho em Porto Alegre - RS. Passados cinco anos, parafraseamos essa pergunta, à medida que nos questionamos: “quais são as imagens de trabalhadores que povoam nossas memórias, nossos corpos, nossos afetos, nossas práticas e nossos saberes, no contexto da pandemia da COVID-19?" Para responder a essa pergunta, o presente ensaio de Antropologia Visual tem o objetivo de narrar, imageticamente, por meio de uma fotoetnografia (Achutti, 1997, 2004, Achutti \& Hassan 2004), o cotidiano citadino de trabalhadores, em suas múltiplas experiências, que, em função das condições sociais ou da profissão que exercem, não têm condições de cumprir as recomendações do distanciamento social, durante a pandemia da COVID-19, na cidade de Cascavel-PR.

Para a execução deste trabalho, pesquisadores vinculados ao Laboratório de Antropologia Visual da Universidade Estadual do Oeste do Paraná colocaram em prática o exercício metodológico, proposto por Ana Luiza Carvalho Rocha e Cornélia Eckert, que consiste em caminhar pela cidade com instrumentos de produção imagética, evocando as múltiplas narrativas que configuram as experiências do viver urbano (Rocha \& Eckert, 2020, p. 22). Como resultados desse caminhar, apresentamos o cotidiano de trabalhadores, que se encontram impossibilitados de adotar a estratégia sanitária, utilizada em vários países, como forma de reduzir a propagação da pandemia do novo Coronavírus e amplamente recomendada pela Organização Mundial da Saúde - OMS, que consiste no distanciamento social.

$\mathrm{O}$ artigo encontra-se estruturado em duas partes. Na primeira, formada por um texto escrito, recorremos ao conceito de apartheid como perspectiva de análise para mostrar seus efeitos no cotidiano de trabalhadores; assim, apresentamos, brevemente, o campo da Antropologia Visual e da fotoetnografia. Por fim, discorremos sobre nosso campo de pesquisa, marcado por profundas evidências de vulnerabilidade e injustiça social. Na segunda parte, formada, essencialmente, por uma linguagem imagética, apresentamos o cotidiano citadino dos nativos. Com essa organização, ao recorrermos às linguagens textual e imagética, oferecemos ao leitor duas possibilidades de entrada para percorrer os múltiplos corredores de interpretações, sendo possível escolher entre iniciar a leitura pelas imagens ou pela escrita textual. 


\section{Metodologia}

Será possível entender uma sociedade por meio dos registros fotográficos do cotidiano? Foi com essa pergunta que Marmanillo (2012, p. 157) iniciou a problematização a respeito dos usos da fotografia na narrativa visual. Passados oito anos dessa eminente reflexão, parafraseamos essa pergunta para propor o seguinte questionamento: é possível explorar alguns dos impactos da COVID-19, no cotidiano de trabalhadores de uma cidade do interior do Paraná? Considerando que a “Antropologia busca compreender todos os tipos de comunicação, as verbais e as não verbais, as imagéticas e as não imagéticas, as concretas e as simbólicas" (Koury, 2004, p. 8), concebemos que, sim, é possível compreendê-la. Eis, portanto, a perspectiva de análise que o presente ensaio visual adota.

A Antropologia Visual brasileira, ao ter seu crescimento vertiginoso, na década de 1980, quando se consolidou no país, em 1990 (Koury, 1998, p. 9), alcançou o posto de agenda de pesquisa consistente, sendo que seu empreendimento está no fomento a outras formas de se construir narrativas etnográficas, isto é: com e por meio de imagens (Rocha \& Eckert, 2014, p. 54). A expansão dessa agenda de pesquisa evidencia-se, conforme bem ressaltou Peixoto (2014, p. 138), no espaço de destaque ocupado pela Antropologia Visual, nas principais associações científicas brasileira (ANPOCS, ABA, SBS, RAM) e nos demais principais congressos científicos do país. Percebemos, portanto, que, se, na década de 1990, a pesquisa visual era "um campo ainda em definição, sem fronteiras delimitadas, por onde o pesquisador ainda caminhava sem muita clareza" (Koury, 1999, p. 49), tal limitação já fora superada, sobretudo, pela contribuição dos pioneiros da Antropologia Visual (Cornelia Eckert e Ana Luiza Carvalho, na UFRGS, Clarice Peixoto na UERJ, Carmem Rial na UFSC, Sylvia Caiuby Novaes na USP, Mauro Koury na UFPB, Etienne Samain na UNICAMP, entre outros).

Considera-se que:

A fotografia é um aprendizado de observação paciente, de elaboração minuciosa de diferentes estratégias de aproximação com o objeto, de desenvolvimento de uma percepção seletiva, de uma vigilância constante e de prontidão para captar o acontecimento no momento do acontecimento. (Leal, 1986, p. 16)

Assim, pesquisadores vinculados ao Laboratório de Antropologia Visual da Universidade Estadual do Oeste do Paraná, saíram a campo em diversos dias, horários e cidades diferentes, para exercitar essa tarefa de observação paciente, defendida por Leal (1986, p. 16), sempre dispostos a captar efeitos da COVID-19, no momento do acontecimento. Se, de acordo com Barthes (1984, p. 61), "a fotografia é subversiva não quando assusta, perturba ou até estigmatiza, mas quando é pensativa", o desafio final desse grupo de pesquisadores é que essas imagens possam fazer o leitor refletir sobre cotidiano dos trabalhadores "protagonistas anônimos da história". (Vainfas, 2000)

A partir dessa experiencia em campo, é apresentado uma narrativa visual, na qual o foco incidiu sobre as:

... formas múltiplas do viver a cidade, das experiências geracionais de continuidade e de descontinuidade nos ritmos urbanos, em que se configuram sociabilidades, redes de trocas, interações em que nossos interlocutores subvertem limites de planejamento e administração urbana, negociam conflitos e rearranjam situações de crise, vulnerabilidade ou imprevisibilidade. (Rocha \& Eckert, 2020, p. 22)

Para alcançar os objetivos propostos, que consistiam em narrar essas múltiplas formas de viver o trabalho, durante a pandemia, optamos por seguir a proposta teórica e metodológica da fotoetnografia, desbravada pelo antropólogo brasileiro, Luiz Eduardo Robinson Achutti (1997, 2004).

Parafraseando Rodolpho et al. (1995, p. 169), por meio da fotoetnografia, o presente texto não se propõe a fazer uma reflexão da Antropologia da Imagem de trabalhadores, mas, sim, efetivar uma Antropologia em imagens de trabalhadores. Afinal: 
A Antropologia Visual vem contribuindo substancialmente com a disciplina antropológica não apenas como material ilustrativo, mas tem sido tomada como uma importante técnica complementar dentro das técnicas de coletas de dados, ou mesmo tem sido utilizada como a principal forma de captação de dados, tornando-se a base da metodologia aplicada. (Rodolpho et al., 1995, p. 169)

Como ressaltou Arlaud (2004, p. 18), a linguagem imagética é da ordem do mostrar: não se demonstra, conta-se, na qual, por meio da fotoetnografia, trata-se de construir uma narrativa, restituir uma realidade pela linguagem fotográfica.

A proposta teórico-metodológica da fotoetnografia consiste em utilizar a fotografia como forma de narrativa integral (Achutti, 2004, p. 74), sem a necessidade de textos, seja na forma de legenda, seja com comentários entre uma imagem e outra. De acordo com Achutti e Hassen (2004, p. 276), o que caracteriza a fotoetnografia é quando o uso da fotografia, em pesquisas etnográficas, deixa de ser meramente ilustrativo e passa a assumir a centralidade da narrativa.

Ao usar a imagem como narrativa etnográfica, a fotografia é utilizada como forma de linguagem. Para o autor, a fotoetnografia consiste no "emprego da antropologia visual enquanto um recurso narrativo autônomo na função de convergir significações e informações a respeito de uma dada situação social” (Achutti, 1997, p. 13). O potencial da fotoetnografia está em realizar descrições densas (Geertz, 1989), por meio de imagens fotográficas. Portanto, chegamos ao momento em que "não se trata mais de conceber as imagens como se fossem cerejas, enfeites sobre o bolo do saber" (Samain, 2014, p. 714). As imagens passaram a ser concebidas como um texto visual, "podendo ser lida, ela própria, como um texto" (Novaes, 2005, p. 111). Na fotoetnografia, a fotografia pode ser considerada em si mesma; dessa forma, assim como se narra por meio de palavras, também, é possível construir uma narrativa por meio de imagens.

Por outro lado, para não cair em armadilhas, é preciso estar atento à ressalva que Achutti e Hassen (2004) fazem ao deixar claro que não se trata de sobrepor as imagens sobre o texto, nem o contrário, visto que um não é mais importante que o outro.

É importante ressaltar que a possibilidade de utilização de imagem não implica o seu uso excludente em relação ao texto. Pelo contrário: texto e imagem podem-se articular de forma complementar com seus aportes específicos. A natureza de texto e de imagem naturalmente é diferente. (Achutti \& Hassen, 2004, p. 277)

O que se propõe, portanto, por meio da fotoetnografia, é a utilização das imagens como forma de escrita, na qual a fotografia recebe a mesma importância que as palavras. Isso, evidentemente, não significa que a fotoetnografia - ao se propor como um texto narrativo em si mesmo - defenda a exclusão da linguagem escrita. Isso, também, não impede, dirá o autor, que a fotoetnografia se utilize da linguagem escrita. "A linguagem fotográfica não toma em absoluto o lugar dos textos escritos, nem se opõe a esses textos, mas se acrescenta a eles. A fotoetnografia é uma proposta como um outro leque de informações, o que permite um olhar diferente". (Achutti, 2004, p. 115)

O que Achutti (2004, p. 109) ressalva é, portanto, o lugar de cada uma dessas linguagens. "A linguagem escrita e a linguagem visual são linguagens diferentes que fornecem informações diferentes e que exigem do leitor operações mentais também diferentes".

É por essa razão que o uso de legendas, por exemplo, é criticado pela fotoetnografia.

É ilusão pensar que se poderá fazer uma narrativa fotográfica de forma mais importante e completa seja escrevendo legendas evidentes embaixo de cada fotografia, seja colocando longos textos com as propostas teóricas do autor a cada três ou quatro fotografias. Resultará disso que o espectador vai se cansar com os constantes apelos textuais que o impedem de verdadeiramente penetrar na sequência da narrativa visual. ... Evidentemente, a complementaridade entre texto e fotografia em um mesmo trabalho pode ser interessante, mas para isso é fundamental que esses dois meios componham dois momentos independentes e solidários a serviço daquilo que o pesquisador quer transmitir. Dessa forma, uma narrativa informa a outra, e as duas juntas informar o leitor. (Achutti, 2004, p. 110) 
Um exemplo sobre como fazer coabitar texto e imagem, na perspectiva fotoetnográfica, sem que a linguagem escrita seja alocada como legenda ou comentários entre fotografias, pode ser encontrado em Achutti (1997). A primeira novidade é que o leitor não encontrará um livro contendo capa e contracapa, como de comum. O livro é composto por duas capas e dividido em duas partes: uma de linguagem escrita, na qual a fotoetnografia e a Antropologia Visual são descritas; e outra, somente de imagens fotoetnográficas. "Isto faz com que o livro possa ser abordado de duas formas" (Oliven, 1997, p. 8). Por essa razão, o presente artigo segue, fielmente, a proposta da fotoetnografia, ao não intercalar textos e imagens com legendas ou comentários entre as fotos. Assim, o leitor poderá escolher as duas formas de leitura: pelo texto ou pelas imagens.

\section{Resultados e Discussão}

Ao problematizar esse assunto, na literatura médica, Ferrari (2020) destacou dois aspectos fundamentais para sua compreensão: a) a Organização Mundial da Saúde passou, oficialmente, a denominar um novo coronavírus humano (SARSCoV-2) como doença de coronavírus (COVID-19); e b) que se trata de uma enfermidade infecciosa grave, a qual pode afetar os pulmões, o trato respiratório, bem como outros sistemas, podendo se espalhar por meio de pequenas gotículas liberadas pelo nariz e pela boca de indivíduos infectados. Em apertada síntese, essa é a descrição da COVID-19. Porém, suas implicações, no cotidiano, são desastrosas e imensuráveis. "Não se trata apenas da agudeza avassaladora da doença que o vírus pode provocar, a COVID-19. Trata-se do modo como a pandemia evidencia muitas camadas de vulnerabilidade". (Segata, 2020, p. 277)

Os efeitos da pandemia, teoricamente, nos fazem lembrar da música dos compositores Claudio Roberto Andrade De Azeredo e Raul Seixas: "No dia em que a Terra parou”, lançada em 1977, que diz: "No dia em que todas as pessoas, do planeta inteiro resolveram que ninguém ia sair de casa, como que se fosse combinado em todo o planeta. Naquele dia, ninguém saiu de casa, ninguém". Isso, no plano teórico, pois, no prático, a realidade, marcada por graves desigualdades sociais, revela que nem todos os trabalhadores foram atingidos da mesma forma pela atual pandemia. Alguns puderam aderir à campanha conhecida nas redes sociais por \#fiqueemcasa. Outros, entretanto, não têm as mesmas condições sociais. Orso (2020) enfatiza que a COVID-19 não gerou desigualdades e injustiças ao Brasil. Ela as publicizou, ampliando ainda mais as distâncias sociais. Ao discutir esse assunto na perspectiva da antropologia da biossegurança, Segata (2020, p. 303) conclui que "o que temos vivido com a COVID-19 é apenas mais um sintoma. A verdadeira doença ainda se chama capitalismo".

Esse marcador das desigualdades sociais, também, nos permite analisar os efeitos da pandemia no cotidiano dos trabalhadores pela perspectiva do apartheid. Se, entre 1948 e 1994, o apartheid africano foi caracterizado, por Sonn e Stevens (2017), além de Pereira (2008), pela segregação racial, na qual a população encontrava-se dividida de acordo com grupos raciais, agora, passados mais de 20 anos de extinção do apartheid africano, por ocasião da COVID-19, Brum (2020, s.p) argumenta que "a pandemia de COVID-19 expôs o apartheid não oficial do Brasil em toda a sua brutalidade. É bem explícito qual é a população que tem o direito a não ser contaminada e qual é a população que aparentemente pode ser contaminada."

Nessa perspectiva de análise, a divisão ocorre, principalmente, entre os trabalhadores que têm condições de aderir às recomendações da Organização Mundial da Saúde - OMS, no sentido de cumprirem o distanciamento social - como forma de reduzir o contágio do vírus -, e aqueles que não têm.

No momento em que esse ensaio visual é construído, o retrato do Brasil, além dos aspectos acima destacados é: colapso dos sistemas de saúde; crise econômica; crise no sistema educacional; inegável descompasso na esfera política, o que produz latente dificuldade para a condução das ações a serem efetivadas no combate à pandemia; Fake News; mais de 400 mil mortes pelo vírus, entre outros fatores, que nos colocam diante de um momento tão delicado da existência humana que, talvez, os Antropólogos, Sociólogos, Historiadores, Médicos, Enfermeiros e outros profissionais passem a interpretar a realidade mundial pela sigla AC/DC - Antes da COVID/Depois da COVID. 
Diariamente, os meios de comunicação e as redes sociais apresentam o cotidiano de trabalhadores, que estão na linha de frente do enfrentamento da COVID-19. São profissionais de diversas áreas, que não têm condições de seguir as orientações do distanciamento social, visto que necessitam continuar trabalhando, para que pessoas, infectadas pela doença, possam ser tratadas. Nessa linha de frente, médicos, enfermeiros e técnicos da área de saúde são diariamente referenciados como protagonistas ou heróis.

Sem desconsiderar o protagonismo desses profissionais, afinal, a atuação deles tem sido decisiva, quando os autores foram às ruas, para captar imagens de trabalhadores, se depararam com uma série de outros profissionais em situações marcadas por profundas evidências de vulnerabilidade e injustiça social e que, também, se constituem como "protagonistas anônimos da história" (Vainfas, 2002), mas que, em função de não serem considerados como aqueles da "linha de frente", estabelecidos pelo padrão midiático, não possuem a mesma visibilidade. É sobre o cotidiano desses trabalhadores que a presente narrativa visual se debruça. Afinal, ao se falar em trabalhadores da "linha de frente" ou heróis, no contexto da COVID-19, convém lembrarmos do poema de Bertold Brecht, intitulado "perguntas de um operário que lê":

Quem construiu as portas de Tebas?

Nos livros constam nomes de reis.

Foram eles que carregaram as rochas?

E Babilônia destruída mais de uma vez?

Quem a construiu de novo?

Quais as casas de Lima dourada

que abrigavam os pedreiros?

Na noite em que se terminou a muralha da China

para onde foram os operários da construção?

A eterna Roma está cheia de arco de triunfo.

Quem os construiu?

Sobre quem triunfavam os césares?

Bizâncio, tão cantada, só consistia de palácios?

Mesmo na legendária Atlântida

os moribundos chamavam pelos seus escravos

na noite em que o mar os engolia.

O jovem Alexandre conquistou a Índia.

Conquistou sozinho?

César bateu os gálicos.

Não tinha ao menos um cozinheiro consigo?

Felipe da Espanha chorou a perda de sua Esquadra.

Só ele chorou?

Frederico II ganhou a guerra dos Sete Anos.

Quem mais ganhou a guerra?

Cada página uma vitória.

Quem prepara os banquetes?

De dez em dez anos um grande homem.

Quem paga as suas despesas?

Tantas histórias.

Tantas perguntas.

(Brecht, 1982, p. 31)

Esse poema se mantém atual, sobretudo, para que reflitamos sobre os trabalhadores que são tão importantes quanto os denominados por "linha de frente", mas que em geral são comumente esquecidos, tais como foram aqueles que Bertold Brecht magistralmente trouxe a baila na reflexão acima. 
Research, Society and Development, v. 10, n. 6, e26710615782, 2021

(CC BY 4.0) | ISSN 2525-3409 | DOI: http://dx.doi.org/10.33448/rsd-v10i6.15782

As lentes das câmeras incidiram, portanto, sobre os trabalhadores de indústrias, comerciários, bancários, agricultores e muitos outros que não podem optar pelo distanciamento social, bem como voltaram-se àqueles cujas condições sociais os obrigam a manter determinadas atividades, mesmo diante do risco de contaminação pelo vírus. O presente ensaio visual narra um cenário que reforça a tese de que:

A pandemia de COVID-19 expôs o apartheid não oficial do Brasil em toda a sua brutalidade. É bem explícito qual é a população que tem o direito a não ser contaminada e qual é a população que aparentemente pode ser contaminada. É explícito tanto por aqueles a quem os empregadores negam o direito de permanecer em isolamento físico, obrigandoos a pegar transporte público e ir para o trabalho em plena pandemia, quanto naqueles que vivem em casas precárias, sem esgoto e muitas vezes sem água, um ou dois cômodos divididos com uma família numerosa, grudados em outras casas com a mesma situação. Pesquisas já mostraram que são os negros, historicamente os mais pobres no Brasil, os que mais morrem de COVID-19. (Brum, 2020, s.p.)

Dentre mais de 2000 (duas mil) imagens capturadas, selecionamos, para este ensaio, 05 (cinco), que narram o cotidiano de trabalhadores durante a pandemia, conforme pode ser observado a seguir:

Figura 1.A, B, C, D, E - Imagens que narram o cotidiano de trabalhadores durante a pandemia.

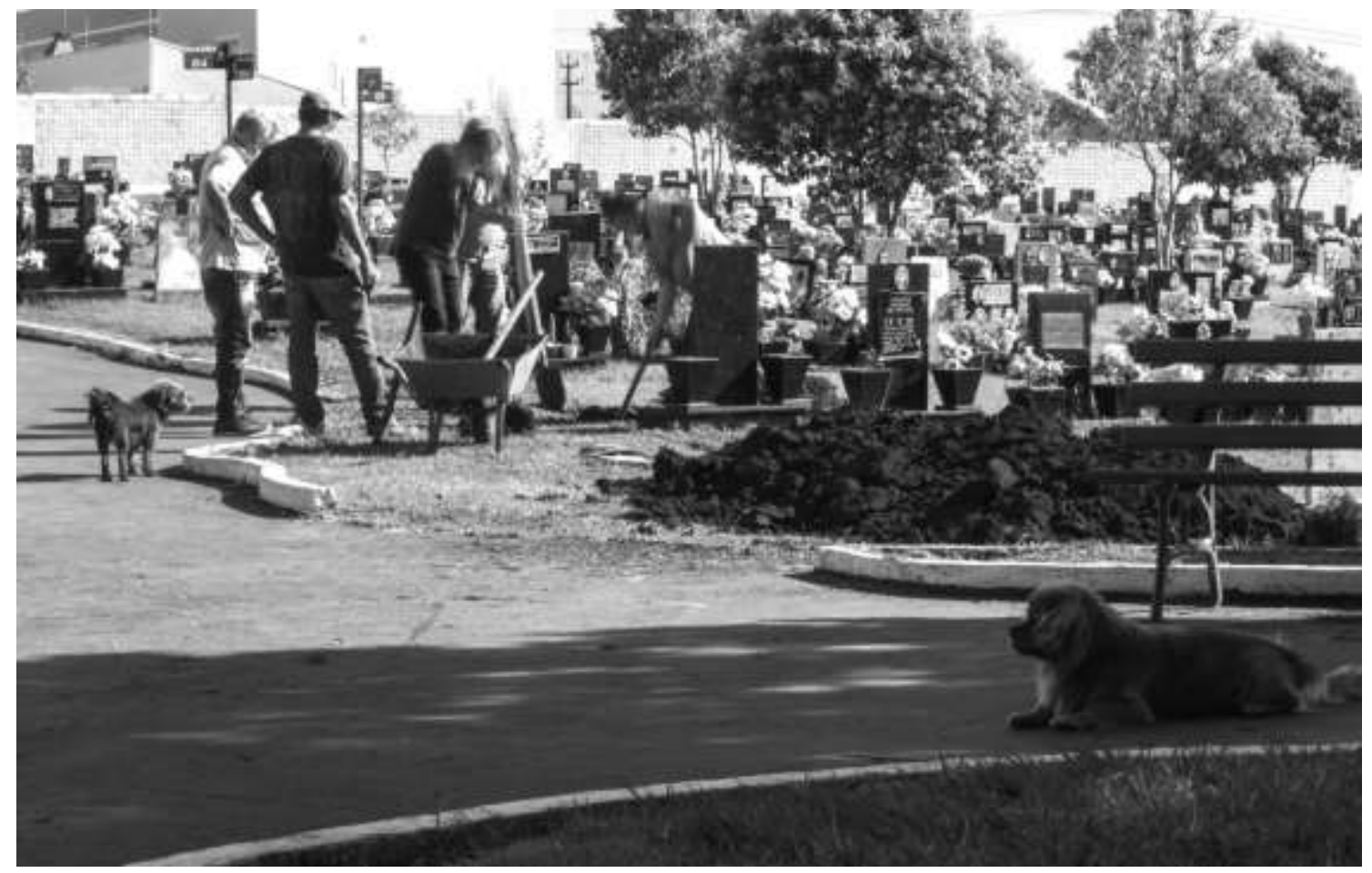


Research, Society and Development, v. 10, n. 6, e26710615782, 2021

(CC BY 4.0) | ISSN 2525-3409 | DOI: http://dx.doi.org/10.33448/rsd-v10i6.15782

B.

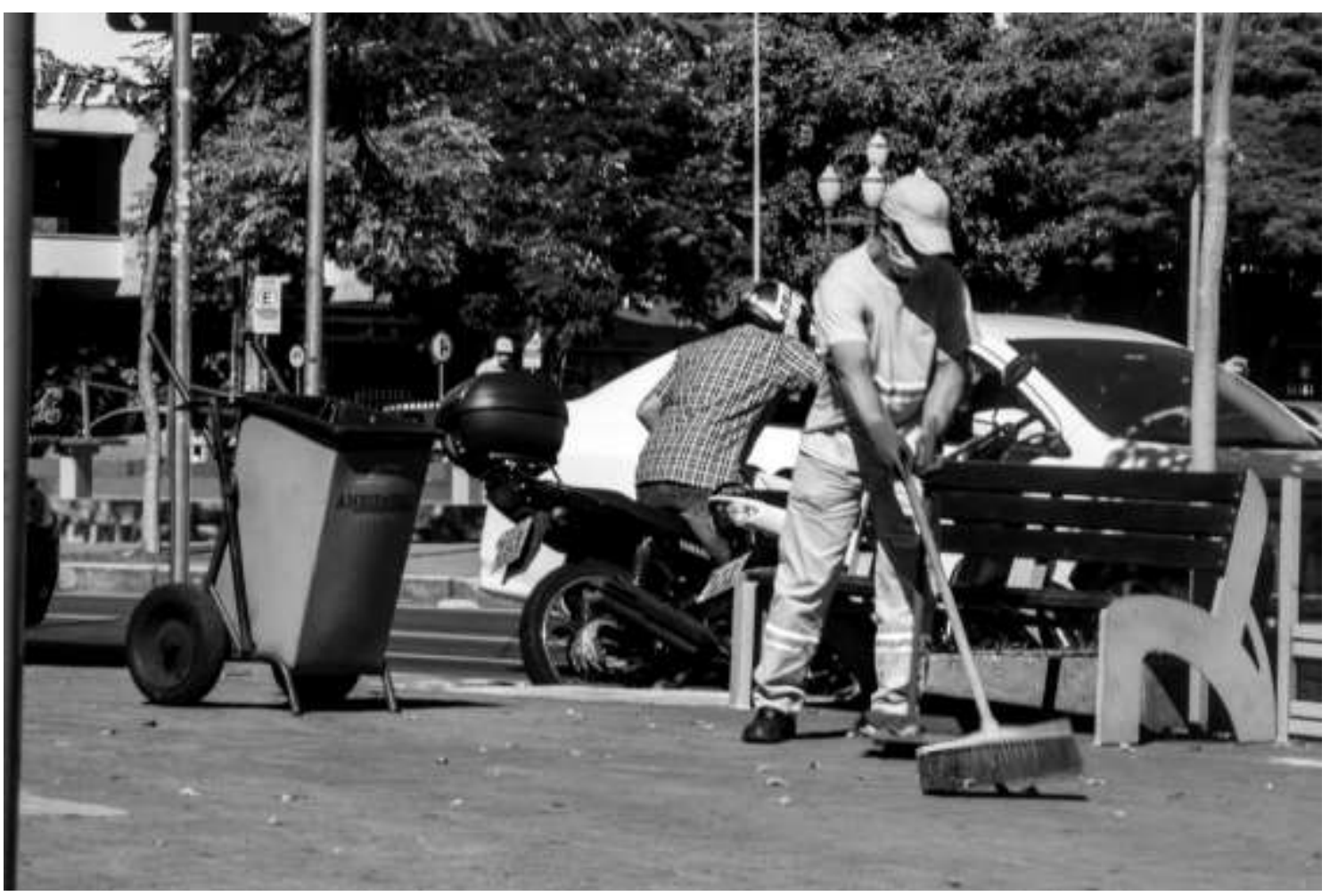

C.

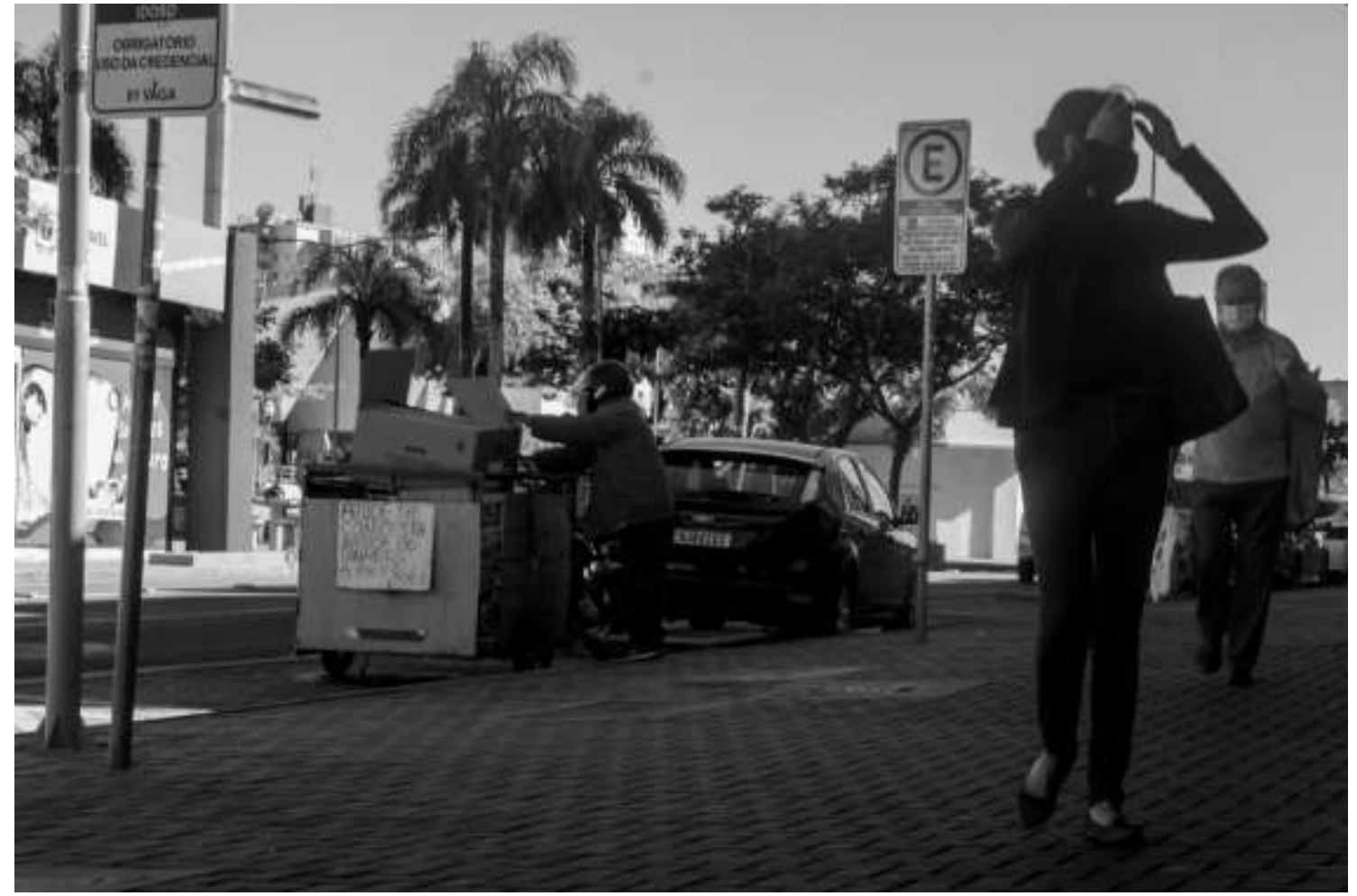


Research, Society and Development, v. 10, n. 6, e26710615782, 2021

(CC BY 4.0) | ISSN 2525-3409 | DOI: http://dx.doi.org/10.33448/rsd-v10i6.15782

D.

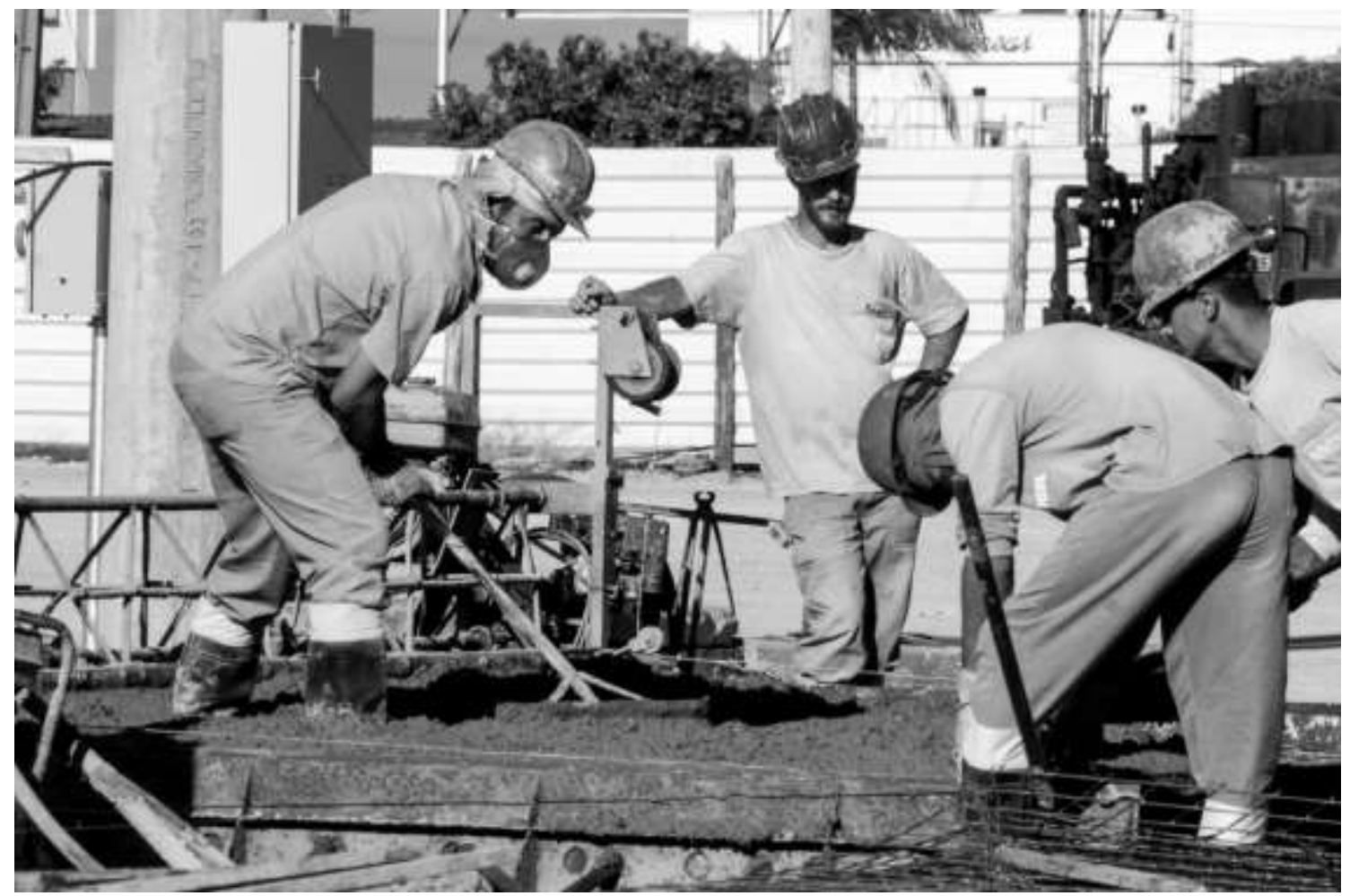

E.

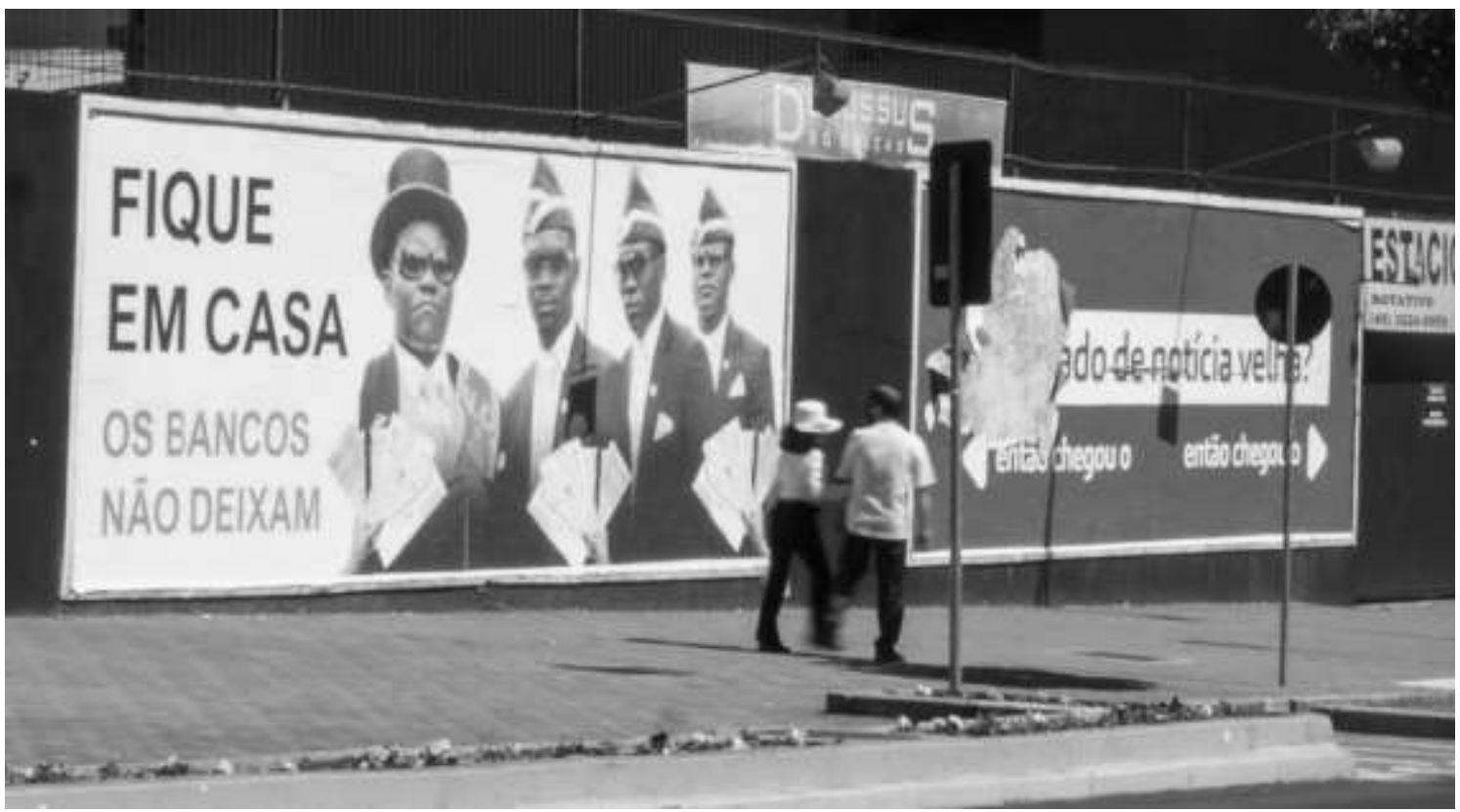

Fonte: Autores.

\section{Considerações Finais}

Ao longo deste artigo demonstramos como a Antropologia saiu à frente, de modo que as imagens não se constituem mais apenas como um "muro de arrimo", de forma a servir de ilustração, auxílio ou anexo do texto escrito. Felizmente, chegamos ao momento em que "não se trata mais de conceber as imagens como se fossem cerejas, enfeites sobre o bolo do saber" (Samain, 2014, p. 714). No cenário brasileiro, é um antropólogo da Universidade Federal do Rio Grande do Sul - 
Research, Society and Development, v. 10, n. 6, e26710615782, 2021

(CC BY 4.0) | ISSN 2525-3409 | DOI: http://dx.doi.org/10.33448/rsd-v10i6.15782

UFRGS, Luiz Eduardo Robinson Achutti, que soube, com total maestria, elaborar um estatuto heurístico da imagem, para que não ficasse refém do texto escrito. Na prática, na década de 1990, ele seguiu as lições de Samain (2014, p. 716), que defende: "é necessário, sobretudo, saber problematizar visualmente, isto é, se perguntar - com relação a um determinado objeto de estudo - de que modo singular tratá-lo sob o regime das imagens”.

Portanto, este trabalho foi estruturado na interface da fotoetnografia, campo da Antropologia Visual e da Antropologia Urbana. Ele é tributário das contribuições teórico-metodológicas, oferecidas por Luiz Eduardo Robinson Achutti e pelas professoras Cornélia Eckert e Ana Luiza Carvalho da Rocha, que, na década de 1980, desbravaram tal campo e, desde então, têm contribuído fortemente para consolidação da Antropologia Visual no Brasil, por meio do Núcleo de Antropologia Visual (NAVISUAL) e do Banco de Imagens e Efeitos Visuais (BIEV).

\section{Referências}

Achuti, L. E. R. (1997). Fotoetnografia: um estudo de antropologia visual sobre cotidiano, lixo e trabalho. Tomo Editorial, Palmarinca.

Achuti, L. E. R. (2004). Fotoetnografia da Biblioteca Jardim. Editora da UFRGS: Tomo Editorial.

Achuti, L. E. R., \& Hassen, M. N. A. (2004). Caderno de campo digital: antropologia em novas mídias. Horizontes Antropológicos, 21 (10), $273-289$.

Arlaud, J. (2004). Prefácio. In L. E. R. Achutti. Fotoetnografia da biblioteca jardim. Editora da UFRGS/Tomo Editorial, 17-20.

Barthes, R. (1984). A câmara clara: nota sobre fotografia. Nova Fronteira.

Brecht, B. (1982). 1898-1956. Antologia poética. Elo Editora.

Brum, E. (2020). A pandemia expôs o apartheid não oficial do Brasil em toda sua brutalidade. Rádio Renascença. https://rr.sapo.pt/2020/04/24/mundo/apandemia-expos-o-apartheid-nao-oficial-do-brasil-em-toda-a-sua-brutalidade/especial/190424/

Collier Junior, J. (1973). Antropologia visual: a fotografia como método de pesquisa. EPU, Editora da Universidade de São Paulo.

Ferrari, F. (2020). COVID-19: Dados Atualizados e sua Relação Com o Sistema Cardiovascular. Arquivos Brasileiros de Cardiologia, 57(26), $275-313$.

Ferraz, A. L. C., \& Mendonça, J. M. (2014). Antropologia visual: perspectivas de ensino e pesquisa. ABA.

Geertz, C. (1989). A interpretação das culturas. Livros Técnicos Científicos.

Koury, M. G. P. (1997). Usos da imagem nas ciências sociais. João Pessoa: Editora Manufatura.

Koury, M. G. P. (1998). Imagens \& Ciências Sociais. Editora Universitária da UFPB.

Koury, M. G. P. (1999). A imagem nas ciências sociais no Brasil: um balanço crítico. BIB - Boletim Informativo e Bibliográfico, $47,49-63$.

Koury, M. G. P. (2001). Imagem e memória: ensaios em antropologia visual. Garamond.

Koury, M. G. P. (2004). Comunicação e Antropologia Visual. In M. G. P. Koury (org). Sociologia da imagem: ensaios críticos, GREI, 8-16.

Leal, E. M. (2020). Trabalhos e relação de classe em tempos de pandemia. Tessituras: Revista de Antropologia e Arqueologia, 1(8), 57-62.

Leal, O. F. (1986). A leitura social da novela das oito. Vozes.

Marmanillo, J. (2012). Lógicas imagéticas de uma sociedade interiorana: usos da fotografia e narrativa visual no Brasil setentrional. Revista Iluminuras, 31(13), 157-176.

Novaes, S. C. (2005). O uso da imagem na Antropologia. In E. Samain (org.). O fotográfico, Editora Senac, 107-113.

Novaes, S. C. (2012). A construção de imagens na pesquisa de campo em antropologia. Revista Iluminuras,31(13), 11-29.

Oliven, R. G. (1997). Prefácio. In L. E. R Achutti (org.). Fotoetnografia: um estudo de antropologia visual sobre cotidiano, lixo e trabalho. Palmarinca, Tomo Editorial, 5-9.

Orso, P. J. (2020). O novo coronavírus, a pedagogia histórico-crítica, a sociedade de classes e o internacionalismo proletário. Revista Exitus, (10), 1-54.

Peixoto, C. E. (2014). Antropologia visual: como transmitir esse conhecimento? In A. L. C Ferraz, \& J. M. Mendonça (orgs.). Antropologia visual: perspectivas de ensino e pesquisa. ABA, 133-140.

Pereira, A. D. (2008). Apartheid: apogeu e crise do regime racista na África do Sul (1948-1994). In J. R. Macedo (org). Desvendando a história da África. Editora da UFRGS, 139-157. 
Research, Society and Development, v. 10, n. 6, e26710615782, 2021

(CC BY 4.0) | ISSN 2525-3409 | DOI: http://dx.doi.org/10.33448/rsd-v10i6.15782

Rocha, A. L. C., \& Eckert, C. (2013a). Antropologia da e na cidade, interpretação sobre as formas da vida urbana. Marcavisual.

Rocha, A. L. C., \& Eckert, C. (2013b). Etnografia de rua: estudos de antropologia urbana. Editora da UFRGS.

Rocha, A. L. C., \& Eckert, C. (2014). Experiências de ensino em antropologia visual e da imagem e seus espaços de problemas. In A. L. C Ferraz, \& J. M. Mendonça (orgs.). Antropologia visual: perspectivas de ensino e pesquisa. ABA, 51-112.

Rocha, A. L. C., \& Eckert, C. (2015). Um projeto antropológico: o estudo da memória do trabalho na cidade moderno-contemporânea. Etnografias do trabalho, narrativas do tempo. Marcavisual, 16-51.

Rocha, A. L. C., \& Eckert, C. (2020). A arte de narrar as cidades: etnografia de (na) rua, alteridades em deslocamento. Revista Hawò, 1(1), 3-51.

Rodolpho, A., Eckert, C., Godolphim, N., \& Rosa, R. (1995). A experiência do Núcleo de Antropologia. Visual - UFRGS. Horizontes Antropológicos. 2 , $175-177$.

Samain, E. (2014). Raízes e asas para as imagens. In A. L. C. Ferraz, \& J. M. Mendonça (orgs.). Antropologia visual: perspectivas de ensino e pesquisa. ABA, 713-718

Segata, J. (2020). COVID-19, biossegurança e antropologia. Horizontes antropológicos, 57(26), 275-313.

Sonn, C., \& Stevens, G. (2017). Histórias do apartheid, memória e pertencimento entre a população da diáspora sul-africana na Austrália. Revista USP, 114, 71-90.

Vainfas, R. (2000). Micro-história: os Protagonistas Anônimos da História. 